Vol. 11 (1): 181-186 (2021)

\title{
ECOLOGICAL ASPECTS OF BIOSECURITY IN MODERN AGROECOSYSTEMS
}

\author{
Lyudmyla Symochko $^{12,3, *}$, Larysa Bugyna ${ }^{2,4}$, Olga Hafiiyak ${ }^{1}$ \\ ${ }^{1 *}$ Uzhhorod National University, Faculty of Biology, Voloshyna Str. 32, 88000, Uzhhorod, Ukraine; \\ ${ }^{2 *}$ RDE Center of Molecular Microbiology and the Mucosal Immunology, Narodna sq.3, 88000, Uzhhorod,Ukraine; \\ ${ }^{3 *}$ Institute of Agroecology and Environmental Management NAAS, Metrologichna Str., 12, Kyiv, 03143, Ukraine; \\ ${ }^{4}$ Uzhhorod National University, Faculty of Medicine, Narodna sq.3, 88000, Uzhhorod,Ukraine; \\ *Corresponding Author Lyudmyla Symochko, e-mail: 1yudmilassem@gmail.com;
}

Received December 2020; Accepted January 2021; Published February 2021;

DOI: https://doi.org/10.31407/ijees11.124

\begin{abstract}
Antibiotic resistance is a serious threat to human health and biosecurity across the world. The soil microbiome plays an important role in the development and spread of antibiotic resistance in humans. The aim of this study was to detect the antibiotic resistance soil bacteria in different agroecosystems. We have isolated 244 dominating bacteria; among of them 53 antibiotic-resistant strains had been detected. The most isolates belonged to multi-drug resistant strains, greater than $62,3 \%$ of which were resistant to 9 antibiotics. A study of the agroecosystems where Capsicum annuum, Vitis vinifera, Rubus idaeus L., Petroselinum crispum were cultivated showed that the microbial community of soil samples have been characterized by a high content of antibiotic-resistant microorganisms. From the soil were isolated antibiotic resistant anaerobic and aerobic microorganisms: Clostridium perfringens, Clostridium oedematiens, Enterobacter cloacae, Enterococcus faecalis, Hafnia alvei, Bacillus megaterium, Bacillus mycoides, and Pseudomonas aeruginosa. Modern agroecosystems are the source of spread of pathogenic and conventionally pathogenic microorganisms with detected multiple antibiotic resistances and potentially endangering of human health.
\end{abstract}

Keywords: agroecosystem, antibiotic resistance, biosecurity, microbiome, soil. 